\title{
PROPOSTA PEDAGÓGICA DE AULA TEÓRICA E PRÁTICA EM UMA TURMA DE AUTOMAÇÃO INDUSTRIAL: ACIONAMENTOS E SEGURANÇA DE MÁQUINAS ELÉTRICAS
}

\author{
PEDAGOGICAL PROPOSAL FOR THEORETICAL AND PRACTICAL CLASS IN AN \\ INDUSTRIAL AUTOMATION CLASS: DRIVING AND SAFETY OF ELECTRICAL \\ MACHINES
}

\section{Mateus Vorpagel ${ }^{1}$}

Samuel Flores ${ }^{2}$

\section{Eniz Conceição Oliveira ${ }^{3}$}

RESUMO: Esse trabalho tem como objetivo apresentar uma proposta pedagógica de aulas teóricopráticas voltadas à área de acionamentos e segurança em máquinas elétricas, a qual foi realizada com alunos do Curso Técnico em Automação Industrial, da Universidade do Vale do Taquari - Univates.

Palavras-chave: Proposta pedagógica, Acionamento e segurança em máquinas elétricas.

ABSTRACT: This work aims to present a pedagogical proposal of theoretical-practical classes focused on the area of drives and safety in electrical machines, which was carried out with students from the Technical Course in Industrial Automation, at the University of Vale do Taquari Univates.

Keywords: Pedagogical proposal, Activation and safety in electric machines.

\section{INTRODUÇÃO}

Esse trabalho apresenta uma proposta pedagógica de oito aulas teórico-práticas aplicadas em uma turma do terceiro semestre do Curso Técnico em Automação Industrial, da Universidade do Vale do Taquari - Univates, que realiza atividades teórico-práticas voltadas à área acionamentos e segurança em máquinas elétricas na disciplina de Automação Industrial I.

\footnotetext{
1 Graduado em Licenciatura em Matemática - Unopar, Graduado em Engenharia Elétrica - Univates, Mestrandoem Ensino de Ciências Exatas - Univates. E-mail:vorpazoo8@gmail.com.

${ }^{2}$ Graduado em Licenciatura em Matemática - Universidade de Santa Cruz do Sul - Unisc, Mestrando em Ensino de Ciências Exatas - Univates. E-mail: samueldflores@universo.univates.br.

${ }^{3}$ Graduada em Química Licenciatura - Universidade Federal do Rio Grande do Sul- UFRGS, Especialista em Ensino de Química, pela UFRGS, Mestre e Doutora em Química - UFRGS. E-mail: eniz@univates.br.
} 
A turma era composta por dezoito estudantes do sexo masculino, com idade média de 25 anos e que buscam um conhecimento diferenciado para ser aplicado no mercado de trabalho.

\section{OBJETIVO}

O objetivo principal deste trabalho é promover o conhecimento teórico-prático para possibilitar que os alunos apliquem os conhecimentos vistos em sala de aula no mercado de trabalho. Tais conhecimentos são de fundamental importância para o aluno, porque em qualquer sistema elétrico (dos setores industrial, predial e residencial), existe algum tipo de máquina ou equipamento que é acionado através de um motor elétrico.

\subsection{Objetivos Específicos}

$\rightarrow$ Interpretar situações do mercado de trabalho em que o aluno consiga aplicar a melhor solução para o problema.

$\rightarrow$ Conhecer o funcionamento de equipamentos de acionamentos elétricos como contatores, botões, sinaleiros, manoplas, relés térmicos.

$\rightarrow$ Saber montar na prática partidas diretas, estrela-triângulo, com inversor de frequência e softstarter.

$\rightarrow$ Diferenciar as características de acionamentos de motores monofásicos e trifásicos.

$\rightarrow$ Conhecer as principais medidas e equipamentos de segurança aplicados na indústria em máquinas elétricas.

$\rightarrow$ Aprender a trabalhar com equipes multidisciplinares.

\section{REVISÃO TEÓRICA}

Os próximos parágrafos irão embasar esse relatório com referenciais teóricos sobre metodologias de ensino, acionamentos e segurança em máquinas elétricas, motores de indução trifásicos, partida direta, partida estrela-triângulo, inversores de frequência, softstarters.

\section{I Metodologias de Ensino}

De acordo com Brighenti (2014), a educação deve ser orientada por metodologias que sejam capazes de atender os objetivos propostos pelos educadores. A metodologia do ensino é compreendida como um conjunto de procedimentos didáticos, que são representados por métodos e técnicas de ensino. Para Nérice (1987), os métodos de ensino são utilizados para alcançar os objetivos do ensino e da aprendizagem, com máxima eficiência, a fim de obter-se o melhor rendimento. Segundo Anastasiou (200I), as escolas jesuítas influenciaram por muitos anos a forma de ensino no Brasil com 
reflexos que permanecem atualmente. Dentre os principais, destacam-se aulas expositivas, memorização de conteúdo, resolução de exercícios e sistema de avaliação por provas escritas.

Segundo Veiga (2006), o professor deve definir as estratégias e técnicas de ensino a serem utilizadas. As técnicas são componentes operacionais das metodologias de ensino, têm caráter instrumental uma vez que intermediam a relação entre professor e aluno, são favoráveis e necessárias nos processos de ensino e de aprendizagem. Para Bianchini (2006), o aluno sente a necessidade de aplicar seu conhecimento adquirido na prática. Em uma disciplina de automação industrial, este conhecimento é aplicado através da montagem de painéis elétricos de partidas de motores, parametrizando inversores de frequência, dimensionando cargas, programando controladores, entre outros. Para o autor, apenas a teoria gera um aprendizado incompleto nos alunos. De acordo com Gil (2015), é essencial planejar cada aula.

\subsection{Acionamentos e Segurança em Máquinas Elétricas}

A seguir serão apresentados os principais tópicos que contemplam o conteúdo de acionamentos e segurança em máquinas elétricas.

\subsection{Motores de Indução Trifásicos}

Segundo Brito (2002), motores de indução trifásicos, também conhecido como MITs, são utilizados em aplicações em que o uso de um motor de corrente contínua (CC) não é viável, devido ao alto custo desse último. O MIT possui baixa eficiência devido a sua estrutura não-linear e multivariável. Sua massa também é elevada quando comparado ao motor CC, porém pelo preço bem mais acessível, manutenção barata e robustez é muito utilizado na indústria.

\subsubsection{Partida Direta}

De acordo com Silva (2015) e Chapman (2013) a partida direta ocorre por meio de ligação direta do motor à rede de energia elétrica. Utiliza-se a tensão nominal da rede de energia. Por ser um processo simples é utilizada com muita frequência quando não é necessário reduzir a corrente de partida que se eleva em até seis vezes o valor da corrente nominal da máquina. Possui baixo custo e quantidade reduzida de dispositivos. É recomendada para motores de até $7,5 \mathrm{CV}$ de potência. 


\subsubsection{Partida Estrela Triângulo}

Segundo Georgini (2018) a partida estrela-triângulo é um método de acionamento de motores elétricos de indução trifásicos. A partida pode ser manual, semiautomática ou automática. O método se baseia na partida do motor em estrela, de modo que a tensão sobre as bobinas seja reduzida, chegando em até $58 \%$ da tensão nominal do motor. Assim, consegue-se reduzir a corrente de partida em até $33 \%$. Após a velocidade nominal ser atingida essa conexão é transformada em triângulo, mantendo-se os parâmetros do motor.

\subsubsection{Inversores de Frequência e Softstarters}

De acordo com Pinheiro (2005) e Becker (2000) os inversores de frequência e as softstarters são equipamentos eletrônicos que são utilizados para partidas suaves de máquinas elétricas. A diferença do inversor para softstarter está no preço e no tipo de aplicação. Os inversores têm valor bem mais elevados em função da sua capacidade de modular a velocidade e a frequência do motor durante sua utilização. Já a softstarter é apenas utilizada para partir o motor e não pode ser usada para modular a velocidade e frequência como o inversor.

\section{PROCEDIMENTOS METODOLÓGICOS}

O desenvolvimento das atividades foi realizado em dois encontros durante duas semanas consecutivas, sendo sempre um encontro semanal. Cada aula teve uma duração de 4 horas/aula, totalizando 8 horas/aula de atividades. O docente ministrou as aulas de forma expositiva, dialogada e explicativa. Foram utilizados os recursos que o laboratório de Máquinas Elétricas da instituição dispõe. Além disso, com uma maleta didática Weg, foi demonstrado na prática o funcionamento dos componentes eletrônicos para partida de motores elétricos.

No primeiro encontro, a aula foi expositiva, dialogada e prática. Nos dois primeiros períodos foram apresentados slides sobre o conteúdo. Nessa etapa, foram ensinados os principais conceitos de cada tipo de partida, bem como vantagens e desvantagens, equipamentos necessários para realizar esse tipo de acionamento. Os equipamentos apresentados para os alunos foram contatores, botoeiras, chaves comutadoras, chaves seccionadoras, tomadas monofásicas e trifásicas tipo macho e fêmea, disjuntores, relés 
térmicos, relés de tempo e interface. Os slides seguintes demonstraram os principais equipamentos de segurança como relé de segurança, sensor magnético e trava magnética de segurança, botão de emergência, botão de rearme, cortina de luz e botão de esforço zero. Após a apresentação dos slides, foi realizada uma reflexão com os alunos sobre a importância de seguirem todas as normas técnicas quando trabalharem com equipamentos elétricos e mecânicos que possam causar algum tipo de dano à saúde.

No quarto e último período foi apresentada a maleta didática da Weg (Figura 3). Com a ajuda dessa maleta foram exemplificados todos os conceitos já definidos anteriormente com os alunos e foi proposto no quadro, um exercício para os alunos resolverem em casa, que foi corrigido na aula seguinte.

Nos dois últimos períodos foi realizada uma gincana técnica com os acadêmicos que teve como objetivo avaliar o rendimento da turma.

A avaliação foi constituída da participação dos alunos em aula, da realização do tema de casa e do desempenho individual na gincana técnica.

\section{RESULTADOS}

As duas noites de aula, divididas em 8 períodos, ocorreram conforme o planejado. $\mathrm{Na}$ primeira noite ministrou-se o conteúdo de acionamentos e segurança em máquinas elétricas. Os slides que foram elaborados para ministrar tal conteúdo, foram apresentados durante os primeiros três períodos, onde revisou-se o conteúdo de motores de indução trifásicos. Além disso, os slides também apresentaram os conteúdos dos quatro principais tipos de acionamentos de motores: partida direta, estrela-triângulo, com softstarter e com inversor de frequência. Também se ministrou o conteúdo de segurança em máquinas elétricas, onde foram vistos os principais dispositivos de segurança existentes no mercado, dentre eles abordou-se o botão de emergência, relé de segurança, sensor magnético e trava magnética de segurança, botão de rearme, cortina de luz e botão de esforço zero.

No último período apresentou-se a maleta didática Weg. Nesse momento, os alunos puderam conhecer de perto os equipamentos de segurança que foram abordados anteriormente. Para finalizar a primeira aula, inseriu-se uma tarefa para os alunos realizarem em casa. O exercício foi elaborar um quadro resumo dos principais tipos de acionamentos vistos em sala de aula de modo que os discentes pudessem fixar o conteúdo. 
No primeiro período da segunda noite de aula, corrigiu-se a tarefa de casa, fazendo um resumo de todo conteúdo visto na aula anterior. Após isso, fez-se uma reflexão com os acadêmicos dos principais dispositivos e equipamentos de segurança que eles encontram nas empresas em que trabalham, bem como, se eles respeitam e utilizam tais dispositivos para sua segurança e de seus colegas. Os estudantes levantaram diversos pontos, como por exemplo, alguns reclamando das condições precárias na empresa em que trabalham, levantando como é importante utilizar todos os equipamentos de segurança corretamente. Esse momento foi muito importante para refletir sobre a real importância do conteúdo estudado.

Nos dois últimos períodos realizou-se a gincana técnica. A turma composta por apenas I3 alunos, visto que 5 faltaram nessa aula, foi dividida em 3 grupos de 3 estudantes e I grupo de 4 estudantes. As 30 perguntas realizadas foram sobre o conteúdo trabalhado até o momento e o percentual de acertos por parte dos alunos foi bem elevado. Considerando que os integrantes dos 3 primeiros grupos poderiam acertar até io perguntas e dois dos integrantes do quarto grupo poderiam acertar até 8 perguntas e os outros dois, até 7 perguntas, a média de acertos ficou bem alta. A Tabela I ilustra o número de acertos de cada aluno. As letras A até L representam os nomes dos alunos.

Tabela r: Número de acertos de cada aluno

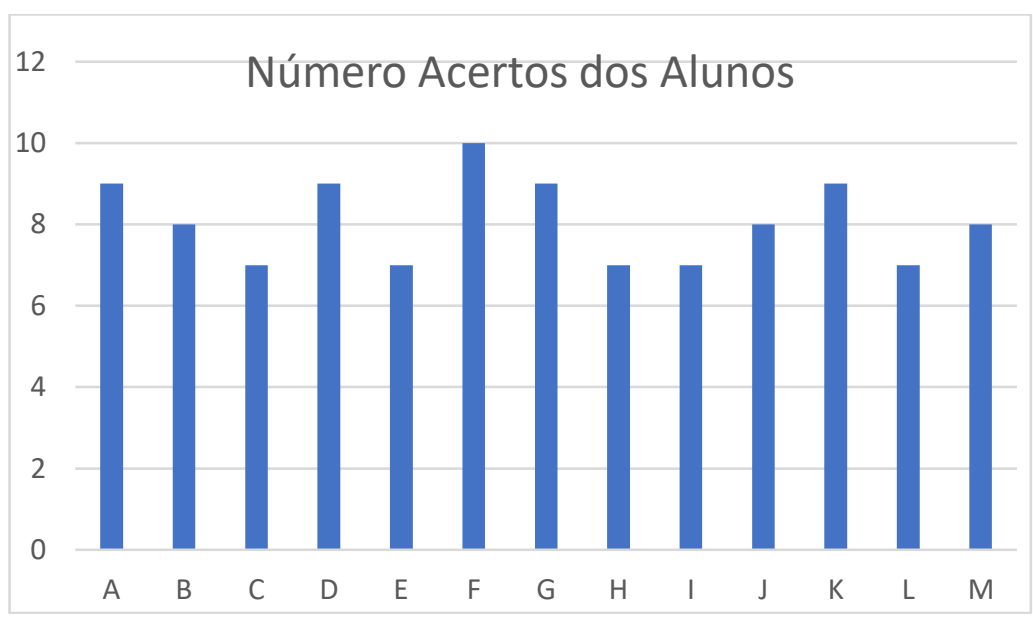

Fonte: O Autor.

Verifica-se na Tabela I que nenhum aluno acertou menos que 70\% das perguntas e que a média da turma foi de 8ı\% de acertos. Tal média não foi maior em função dos alunos do último grupo terem respondido menos perguntas em razão de possuírem um integrante a mais. A Tabela 2 apresenta o número de acertos de cada grupo, onde verifica-se o desempenho coletivo da turma. 
Tabela 2: Número de acertos de cada grupo

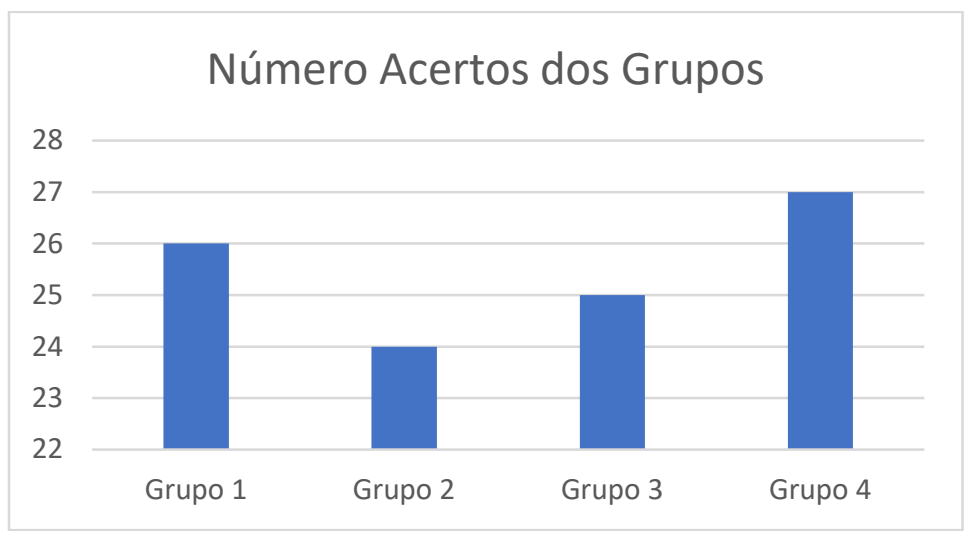

Fonte: O Autor.

A partir da Tabela 2 pode-se verificar que a média de acertos dos grupos foi de $85 \%$ e o grupo que mais acertou atingiu a marca de 27 acertos, totalizando $90 \%$ de aproveitamento.

\section{CONCLUSÃO}

As aulas ministradas obtiveram resultado satisfatório, visto que toda a turma interagiu, para que pudesse se construir um conhecimento sólido. Os alunos se mostraram motivados em relação a metodologia para apresentar-lhes o conteúdo. A inserção da maleta didática da Weg, em que os alunos puderam mexer e conhecer na prática como funcionam os principais dispositivos de segurança existentes no mercado de trabalho, foi fundamental para o enriquecimento das aulas. A forma como os alunos foram avaliados, através de uma gincana técnica, também os motivou, pois fugiu da metodologia tradicional de avaliação, como provas individuais e sem consulta.

Os discentes passaram uma impressão positiva quando foram questionados quanto ao nível de aprendizagem que eles obtiveram ao longo das aulas. Além disso, a avaliação quantitativa dos resultados obtidos na gincana técnica, mostrou que os acadêmicos dominaram os conteúdos lecionados durante esse período de experiência.

\section{REFERÊNCIAS BIBLIOGRÁFICAS}

ANASTASIOU, L. G. C. Metodologia de Ensino na Universidade Brasileira: elementos de uma trajetória. Campinas: Papirus, 20oI.

BECKER, James A.; VON ECKROTH, Kurt; WIELOCH, Christopher J. Integrated soft starter for electric motor. U.S. Patent n. 6,087,80o, in jul. 2000.

BIANCHINI, D., et al. O ensino de engenharia por meio de laboratórios virtuais de eletrônica: uma reflexão entre a montagem no protoboard e a simulação. Anais do XXXIV COBENGE. Passo Fundo, Set. 2006. Disponível em: https://www.researchgate.net/publication/242676686_O_ENSINO_DE_ENGEN 
HARIA_POR_MEIO_DE_LABORATORIOS_VIRTUAIS_DE_ELETRONICA_UMA_REFLE XAO_ENTRE_A_MONTAGEM_NO_PROTOARD_E_A_SIMULACAO>. Acesso em: i3 de abril de 2019.

BRITO, Jorge Nei et al. Desenvolvimento de um sistema inteligente híbrido para diagnóstico de falhas em motores de indução trifásicos. 2002.

BRIGHENTI, J. et al. Metodologias de ensino-aprendizagem: uma abordagem sob a percepção dos alunos. Revista Gestão Universitária na América Latina - GUAL - UFSC, Florianópolis, SC, 2014. Disponível em: 〈https://periodicos.ufsc.br/index.php/gual/article/download/1983-4535.../30483〉. Acesso em: is de abril de 2019.

CHAPMAN, Stephen J. Fundamentos de Máquinas Elétricas. Porto Alegre, AMGH, 2013.

GEORGINI, Joao Marcelo. Automação Aplicada-Descrição e implementação de Sistemas Sequenciais com PLCs. Editora Saraiva, 2018.

GIL, Antonio Carlos. Didática do ensino superior. Atlas, 2015.

NÉRICE, I. G. Didática geral dinâmica. ıo ed., São Paulo: Atlas, 1987.

PINHEIRO, Humberto et al. Modulação space vector para inversores alimentados em tensão: uma abordagem unificada. Sba: Controle \& Automação Sociedade Brasileira de Automaticão, v. I6, n. I, p. 13-24, 2005.

SILVA, Fernando Bento et al. Atenuação do afundamento de tensão em geradores síncronos isolados quando submetidos a partida direta de motores de indução. Dissertação de Mestrado. Universidade Federal de Uberlândia. 2015.

VEIGA, I. P. A. Técnicas de ensino: novos tempos, novas configurações. Papirus Editora, 2006. 